\title{
The future of cardiac surgery training: A survival guide
}

\author{
Michael A. Borger, MD, PhD
}

From the Department of Cardiac Surgery, Leipzig Heart Center, Leipzig, Germany.

Disclosures: Author has nothing to disclose with regard to commercial support.

Received for publication April 21, 2017; accepted for publication April 22, 2017; available ahead of print May 23, 2017.

Address for reprints: Michael A. Borger, MD, PhD, Director of Cardiac Surgery, Leipzig Heart Center, Struempellstrasse 39, Leipzig 04289, Germany (E-mail: michael.borger@ helios-kliniken.de).

J Thorac Cardiovasc Surg 2017;154:994-5

$0022-5223 / \$ 36.00$

Copyright $(C 2017$ by The American Association for Thoracic Surgery

http://dx.doi.org/10.1016/j.jtcvs.2017.04.060

In the current issue of the Journal, Pelletier and colleagues ${ }^{1}$ discuss future training of residents in an era of rapid evolution within the field of cardiac surgery. With an increasing number of cardiac surgery procedures being performed by interventional cardiologists, one could even question whether cardiac surgery has any future whatsoever. My answer to this question would be an emphatic, "Yes," but with several qualifications. The future cardiac surgeon should be intimately familiar with simulators, facile with basic wire skills, subspecialized, and fully committed. In addition, practice changes will be required to deal with the new reality of structural heart disease management. Each of these aspects is discussed here.

Pelletier and colleagues ${ }^{1}$ discuss the need for cardiac surgery simulators in detail in their article, but a more stratified approach will probably be required. Low-fidelity models would be acceptable for residents at the beginning of their training, but increasingly high-fidelity models will be required for senior residents, fellows, and practicing surgeons. Ultra-high fidelity models should be developed, including a full mock-up of the operating room with whichever anatomic model (eg, porcine, ovine, cadaver) that best suits the procedure or device in question, with mechanical pumps and perfusates for those procedures requiring a beating-heart technique. ${ }^{2}$ There will be an increasing need for such simulators as the complexity of our operations increases and the number of "straightforward" procedures being performed decreases.

Basic wire skills will also be required for a variety of cardiac operations. The trend towards minimally invasive and hybrid procedures will continue as patient demand increases and technology improves, and some form of wire skills will be required for most of these procedures. As stressed by Pelletier and colleagues, ${ }^{1}$ future cardiac surgery trainees will need to dedicate at least a few months of their training to services where they can acquire these basic skills.

Subspecialization will be absolutely essential for future cardiac surgeons. The days of cardiac surgeons performing all types of cardiac procedures-and even pediatric or thoracic operations-will be gone in the foreseeable future.

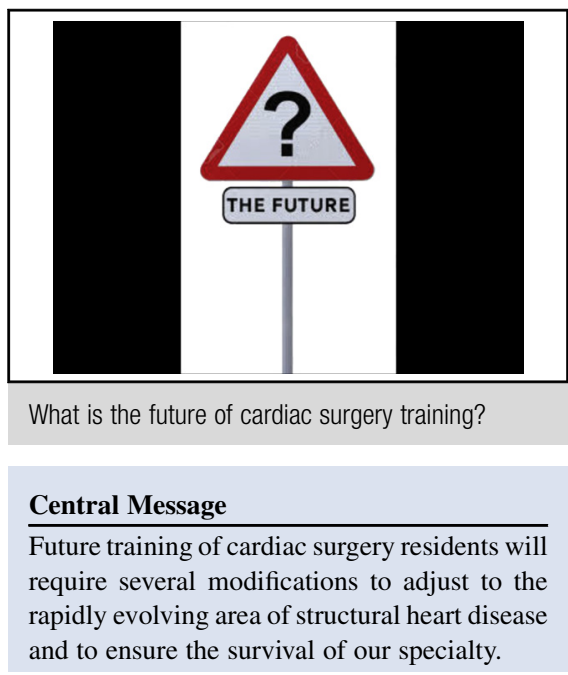

See Article page 990

Medical knowledge is growing at an explosive rate, with an estimated doubling time of 3 months in the foreseeable future, ${ }^{3}$ making it impossible for clinicians to stay on top of essential knowledge within all the different cardiac surgery subspecialties. As stated by Pelletier and colleagues, future trainees will serve themselves well to arrange for at least 1 year of fellowship in an area of a subspecialization, preferably at a large-volume center and in an area that will benefit their future practice group.

Future trainees will also need to be very dedicated to their profession, as was the case for their predecessors. Our profession demands a certain level of technical competence that requires regular exposure to the operating room. Lifelong education - as trainees and as independent surgeons- will be required, including regular participation in continuing medical education events and regular use of simulators.

Any discussion of training of cardiac surgeons should also address the initial period when surgeons start to operate independently. As more and more straightforward structural heart pathologies are treated with transcatheter techniques, fewer opportunities will be available for residents to perform procedures during their training. A greater proportion of cardiac operations will be combined, high-risk, and reoperative procedures. In this regard, the previously accepted practice of leaving the first-year surgeon alone to deal with a type A dissection or double valve endocarditis while "on-call" should no longer be tolerated. Two profound changes will be required to help alleviate this problem.

First, senior surgeons will need to help their more junior colleagues with difficult urgent and emergent operations. 
An effective method of encouraging such mentoring would be public reporting of center-specific results for most cardiac procedures. Public reporting of center-specific results would lead to a host of institutional changes that would encourage a more team-based approach to complex cases, and has several advantages relative to the more problematic public reporting of surgeon-specific results. ${ }^{4}$ Senior surgeons who have a vested interest in their center's survival will be more willing to take the time to guide their junior colleagues through difficult procedures.

Second, very complex and highly specialized procedures will require more centralization. Just as individual surgeons cannot be expected to be up-to-date on every subspecialty of cardiac surgery, individual institutions will not have the expertise to perform every type of operation. Patients requiring complex aortic arch or endovascular procedures, for example, will need to be referred to aortic centers of excellence. Such a practice not only is the right thing to do for our patients, but it is also the right thing to do for our profession.

The current generation of cardiac surgeons has an obligation to our future colleagues and to their future patients. Alterations to our methods of training and to our methods of practice will be required to deal adequately with the rapidly evolving field of cardiac surgery and structural heart disease.

\section{References}

1. Pelletier MP, Kaneko T, Peterson MD, Thourani VH. From sutures to wires: the evolving necessities of cardiac surgery training. J Thorac Cardiovasc Surg. 2017; 154:990-3.

2. Leopaldi AM, Vismara R, van Tuijl S, Redaelli A, van de Vosse FN, Fiore GB, et al. A novel passive left heart platform for device testing and research. Med Eng Phys. 2015;37:361-6.

3. Densen P. Challenges and opportunities facing medical education. Trans Am Clin Climatol Assoc. 2011;122:48-58

4. Jahangiri M, Bilkhu R, Borger M, Falk V, Helleman I, Leigh B, et al. The value of surgeon-specific outcome data: results of a questionnaire. Eur J Cardiothorac Surg. 2016;50:196-200. 